\title{
The difference in transfer of all-rac- $\alpha$-tocopherol stereo-isomers to milk from cows and the effect on its oxidative stability
}

\author{
Tina Slots ${ }^{\mathrm{a}}$, Leif H. Skibsted ${ }^{\mathrm{b}}$, Jacob Holm Nielsen ${ }^{\mathrm{a}, *}$ \\ ${ }^{a}$ Department of Food Science, Research Centre Foulum, Danish Institute of Agricultural Sciences, P.O. Box 50, DK-8830 Tjele, Denmark \\ ${ }^{\mathrm{b}}$ Department of Dairy and Food Science, Food Chemistry, The Royal Veterinary and Agricultural University, \\ Rolighedsvej 30, DK-1958 Frederiksberg C, Denmark
}

Received 12 December 2005; accepted 27 September 2006

\begin{abstract}
Experiments were conducted to study the effect of all-rac- $\alpha$-tocopheryl acetate supplementation of the diet of dairy cows on the oxidative stability of milk. In experiment I the cows' feed was supplemented with 2600 IU per day per cow and in experiment II with $3400 \mathrm{IU}$ and high amounts of unsaturated fat to get the milk more susceptible to oxidation. The content of $\alpha$-tocopherol in milk was determined before and after supplementation, and the percentage increase of $\alpha$-tocopherol in the milk in the two experiments was $37 \%$ and $29 \%$, respectively. The native stereo-isomer ( $R R R$ - $\alpha$-tocopherol) made up $84.3 \%$ (experiment I) and $88.8 \%$ (experiment II) of the isomers, indicating that transfer of the synthetic stereo-isomers to the milk was low. The milk was further exposed to fluorescent light or added copper. Milk with a high content of unsaturated fatty acids and high concentrations of $\alpha$-tocopherols was more susceptible to oxidation than the milk with low $\alpha$-tocopherol content.
\end{abstract}

(C) 2006 Elsevier Ltd. All rights reserved.

Keywords: All-rac- $\alpha$-tocopheryl acetate; Feed supplements; Cows' milk; $\alpha$-tocopheryl stereo-isomers; Oxidative stability

\section{Introduction}

Oxidized flavour, a major defect in milk and other dairy products, is caused by volatiles produced by oxidative cleavage of the unsaturated fatty acids present in phospholipids and triglycerides (Dunkley, Ronning, Franke, \& Robb, 1967; Schingoethe, Parsons, Ludens, Schaffer, \& Shave, 1979). The oxidative stability of milk is also affected by the balance between pro- and anti-oxidative factors such as the content of transition metal ions, the content of lowmolecular anti-oxidants, and the relative activity of proand anti-oxidative enzymes (Nielsen, Østdal, \& Andersen, 2002).

The most important lipid-soluble chain-braking antioxidant found in milk has been identified as $\alpha$-tocopherol, also known as vitamin E (Dunkley et al., 1967; Niki, Yamamoto, Takahashi, Komuro, \& Miyama, 1989; Schingoethe et al., 1979), and it is believed to act as a

\footnotetext{
${ }^{*}$ Corresponding author. Tel.: + 4589991163 ; fax: +4589991564.

E-mail address: JacobH.Nielsen@agrsci.dk (J.H. Nielsen).
}

physical or chemical quencher of singlet oxygen (Gorman, Gould, Hamblett, \& Standen, 1984). Several studies of spontaneous oxidized flavour in milk have shown that a low level of $\alpha$-tocopherol in the feed is critical for the oxidative stability of the raw milk (Charmley, Nicholson, \& Butler, 1991; Krukovsky, Whiting, \& Loosli, 1950; Schingoethe, Parsons, Ludens, Tucker, \& Shave, 1978; Schingoethe et al., 1979; St-Laurent, Hidiroglou, Snoddon, \& Nicholson, 1990).

The composition of the cows' feed affects the concentration of $\alpha$-tocopherol in the milk, and Havemose, Weisbjerg, Bredie, and Nielsen (2004) have shown that milk from cows fed with grass silage had a higher concentration of $\alpha$ tocopherol than milk from cows fed with corn silage. Furthermore, in an earlier study by Schingoethe et al. (1979), it was shown that $\alpha$-tocopherol in the feed is progressively oxidized during storage of the feed, leading to inadequate $\alpha$-tocopherol intake by the cows especially during winter and spring months. Synthetic $\alpha$-tocopherols called all-rac- $\alpha$-tocopherol (IUPAC-IUB, 1982) show varying isomeric distribution, and some preparations are 
composed of equal parts of the eight stereo-isomers $R R R$, $R R S, R S R, R S S, S S S, S S R, S R S$, and $S R R$. Feeding the cows a high level of all-rac- $\alpha$-tocopheryl acetate has been the basis for control of spontaneous oxidation in milk. Several studies indicated that such an increased intake of vitamin $\mathrm{E}$ supplements by cows increases the $\alpha$-tocopherol content of milk (Atwal, Hidiroglou, Kramer, \& Binns, 1990; Charmley \& Nicholson, 1994; Charmley, Nicholson, \& Zee, 1993; Goering et al., 1976; Nicholson \& St-Laurent, 1991; St-Laurent et al., 1990). Atwal et al. (1990) supplemented the diet with 8000 to 10000 IU of all-rac- $\alpha$ tocopheryl acetate per cow per day and found an increase in milk tocopherol of between 17 and $34 \mu \mathrm{g}$ per g milk fat. It is generally recommended that a herd with the spontaneous oxidized flavour problem should be given $3000 \mathrm{IU}$ per day of $\alpha$-tocopherol, but such a practice does not overcome the problem in all cases: e.g., St-Laurent et al. (1990) have shown that the transfer of dietary synthetic $\alpha$-tocopherol to milk is low, and that supplements of $3000 \mathrm{IU}$ of synthetic $\alpha$-tocopherol per cow per day only had minor effects on milk $\alpha$-tocopherol concentration and on the resistance of milk to oxidation.

Synthetic tocopherols are widely used as food and feed additives despite being isomeric mixtures. The native form found in plant material, however, is solely the $R R R$-stereoisomer (Riss, Kormann, Glinz, Walther, \& Ranalder, 1994). The absorption and excretion kinetics for the individual stereo-isomers have not been investigated, and it is unclear whether all stereo-isomers of $\alpha$-tocopherol are absorbed and transported to milk where they can protect milk against oxidation. The higher concentration of $\alpha$ tocopherol in milk from cows, where the feed is supplemented by all-rac- $\alpha$-tocopheryl acetate, is expected to diminish photooxidation.

To further investigate the effect of supplementation with all-rac- $\alpha$-tocopheryl acetate on the oxidative stability of milk, milk samples were exposed to fluorescent light or treated with copper(II) sulphate (a pro-oxidant), and the decline in $\alpha$-tocopherol and increase in hexanal, an indicator of oxidation, were measured. Free radical production was also measured in milk treated with copper(II) sulphate.

\section{Materials and methods}

\subsection{Chemicals and materials}

All-rac- $\alpha$-tocopherol standard, $R R R$ - $\alpha$-tocopherol standard, fatty acid methyl esters for standards, copper(II) sulphate pentahydrate $(99 \%)$, and ascorbic acid were obtained from Sigma Chemical Co. (St. Louis, MO, USA); methanol high-performance liquid-chromatography grade (HPLC grade), sodium chloride, and acetic acid (99.8\%; analytical grade) were from J.T. Baker (Deventer, The Netherlands); sodium hydroxide was from Merck KGaA (Darmstadt, Germany); sodium for sodium methylate was from Merck-Schuchardt \& Co. (Hohenbrunn,
Germany); $n$-heptane (99\%; HPLC grade), chloroform (HPLC grade), and 2-propanol (HPLC grade) were from LabScan Ltd. (Co. Dublin, Ireland); $n$-hexane (HPLC grade) and pentane (HPLC grade) were from Rathburn Chemicals Ltd. (Walkerburn, Scotland); ethylene glycol dimethyl ether (HPLC grade) and dimethyl sulphate $(99+\%)$ were from Sigma-Aldrich Chemie GmbH (Steinheim, Germany), ethanol (96\%,v/v) was from the Danish Destillers (Copenhagen, Denmark), and the water used was purified through an Elgastat Maxima unit (USF Elga, High Wycombe, UK) prior to use.

\subsection{Experimental set-up}

Two separate experiments were designed to investigate the effect of the supplementation of cows' feed by all-rac- $\alpha$ tocopheryl acetate on the oxidative stability of milk and to study the stereo-selectivity in excretion of $\alpha$-tocopherol to milk based on analysis of distribution of the stereo-isomers of $\alpha$-tocopherol.

Experiment I: In this preliminary study four Holstein cows in mid-lactation were fed a diet containing whole crop barley $(10 \%)$, beet molasses $(2.7 \%)$, barley straw $(2.5 \%)$, maize silage $(36 \%)$, rapeseed cake $(8 \%)$, rolled barley $(5.6 \%)$, grass silage $(34.5 \%)$, and minerals $(0.65 \%)$ supplemented with all-rac- $\alpha$-tocopheryl acetate (Trouw Nutrition Denmark A/S, Vejen, Denmark). The standard supplementation of the feed with all-rac- $\alpha$-tocopheryl acetate was withdrawn in a six day wash-out period followed by a supplementation period of three days with high concentrations of $\alpha$-tocopherol of approximately 10 times the normal dose ( $2600 \mathrm{IU}$ per day of all-rac- $\alpha-$ tocopheryl acetate). Milk samples from the morning milking were collected on the last day of the wash-out period (day 0) and on the last day of the supplemental period (day 3). The milk samples from the four cows in each sample day were pooled and analysed for the content of $\alpha$-tocopherol. These two pooled milk samples, before and after supplementation, were exposed to fluorescent light at $2200 \mathrm{~lx}$, and the development of the oxidation product hexanal and the degradation of $\alpha$-tocopherol were followed for $24 \mathrm{~h}$ at $4{ }^{\circ} \mathrm{C}$.

Experiment II: Based on the conclusion from experiment I, i.e., that there was no effect of supplementation by all$r a c-\alpha$-tocopheryl acetate on the oxidative stability of milk despite different levels of $\alpha$-tocopherol present, a new experiment was designed in which dairy cows received feed with a high content of unsaturated fatty acids. The feed was depleted of all-rac- $\alpha$-tocopheryl acetate supplementation for a longer period prior to supplementation with higher amounts by all-rac- $\alpha$-tocopheryl acetate than in experiment I. Three Holstein cows in mid-lactation were fed a diet with toasted soya beans as a feed with high content of unsaturated fatty acids, and no supplementation was given for 26 days, followed by a period of 16 days in which the feed was supplemented with 3400 IU of all-rac- $\alpha$ tocopheryl acetate per day. The feed consisted of grass 
silage $(77.2 \%)$, barley straw $(2.8 \%)$, dried beet pulp $(7.4 \%)$, oats $(4.2 \%)$, toasted soya beans $(8.1 \%)$, and minerals $(0.24 \%)$. The milk was collected just before supplementation (day 0 ) and 16 days after supplementation (day 16) had begun. Again the milk from each sample day was pooled, analysed for the content of $\alpha$-tocopherol and sub-sampled. The sub-samples were subjected to two prooxidative treatments. One milk sub-sample was exposed to fluorescent light at $2200 \mathrm{~lx}$ for $24 \mathrm{~h}$ at $4{ }^{\circ} \mathrm{C}$, and one milk sub-sample was mixed with copper(II) sulphate to an end concentration of $25 \mu \mathrm{M}$ for $24 \mathrm{~h}$ at $4{ }^{\circ} \mathrm{C}$ in order to initiate oxidation. The development of hexanal and the degradation of $\alpha$-tocopherol were followed in these two subsamples during the $24 \mathrm{~h}$ storage period. The depletion of ascorbyl radicals in the milk with added copper(II) sulphate was also followed but with an end concentration of $100 \mu \mathrm{M}$.

\subsection{Extraction methods}

\subsubsection{Extraction of tocopherols from the feed}

The extraction of tocopherols from the feed was carried out as described by Jensen et al. (1998), with minor modifications. A representative sample of feed $(25 \mathrm{~g})$ was frozen in liquid nitrogen and finely ground with an Ultra Turrax T25 (Janke \& Kunkel GmbH \& Co., IKA Labortechnik, Staufen, Germany). The ground feed $(1.00 \mathrm{~g})$ was suspended in a mixture of $96 \%(\mathrm{v} / \mathrm{v})$ ethanol $(24.0 \mathrm{~mL})$, methanol $(9.0 \mathrm{~mL}), 10 \%(\mathrm{w} / \mathrm{v})$ ascorbic acid in water $(10.0 \mathrm{~mL})$, and $50 \%(\mathrm{w} / \mathrm{v}) \mathrm{KOH}$ in water $(7.0 \mathrm{~mL})$. The headspace over the sample was replaced by argon, and the sample was saponified in the dark for $30 \mathrm{~min}$ at $70^{\circ} \mathrm{C}$ and subsequently cooled on ice. The saponified sample $(2.0 \mathrm{~mL})$ was diluted with water $(0.5 \mathrm{~mL})$. The tocopherols were extracted with heptane by adding $5.0 \mathrm{~mL}$ twice to the sample, centrifuging at $1700 \times g$ for $5 \mathrm{~min}$ following each addition and transferring both heptane layers to another container after each centrifugation.

\subsubsection{Extraction of tocopherols from the milk}

The extraction of tocopherols from the milk was carried out as described by Havemose et al. (2004), with minor modifications. Milk $(2.0 \mathrm{~mL})$ and acetic acid in ethanol $(2.0 \mathrm{~mL} ; 1 \%, \mathrm{v} / \mathrm{v})$ were mixed for $10 \mathrm{~s}$. Saturated $\mathrm{KOH}$ in water $(0.30 \mathrm{~mL})$ was added. The dispersion was mixed for $10 \mathrm{~s}$, and subsequently heated to $70^{\circ} \mathrm{C}$ for $60 \mathrm{~min}$. The saponified dispersion was cooled on ice, and demineralized water $(1.0 \mathrm{~mL})$ and heptane $(3.0 \mathrm{~mL})$ were added. The dispersion was mixed again for $1 \mathrm{~min}$, and centrifuged for $3 \mathrm{~min}$ at $1700 \times g$. The upper layer was isolated and either filtered into a HPLC vial for separation and quantification, or the $\alpha$-tocopherol stereo-isomers were derivatized to methyl ether. This derivatization was performed as described by Riss et al. (1994), with minor modifications. The extracted tocopherol mixture $(2.0 \mathrm{~mL})$ was evaporated under nitrogen to dryness and desolved in $n$-heptane $(500 \mu \mathrm{L})$. Ethylene glycol dimethyl ether $(200 \mu \mathrm{L})$ was added, and the solution was stirred during the whole derivatization procedure. Saturated sodium hydroxide $(100 \mu \mathrm{L})$ was added dropwise to the tocopherol mixture followed by addition of dimethyl sulphate $(120 \mu \mathrm{L})$. The headspace over the samples was replaced by argon, and the samples were incubated for $1 \mathrm{~h}$ at room temperature. After incubation, dimethyl sulphate $(60 \mu \mathrm{L})$ was added, and the samples were incubated for $2 \mathrm{~h}$ at room temperature. Subsequently, they were dried under nitrogen at $40^{\circ} \mathrm{C}$. Demineralized water $(400 \mu \mathrm{L})$ was added to the dried sample, and the $\alpha$-tocopheryl methyl ethers were extracted twice using $n$-hexane $(2.0 \mathrm{~mL})$. The organic phase containing $\alpha$-tocopheryl stereo-isomers was separated from the aqueous phase by centrifugation at $1700 \times g$ for $5 \mathrm{~min}$ and subsequently concentrated to $1 \mathrm{~mL}$ by evaporation prior to HPLC analysis.

\subsubsection{Extraction of fat from milk}

The extraction of fat from the milk was carried out as described by Havemose et al. (2004) with minor modifications. Milk fat was extracted from milk by adding methanol $(2.0 \mathrm{~mL})$ and chloroform $(4.0 \mathrm{~mL})$ to milk $(2.0 \mathrm{~mL})$. This mixture was firmly mixed for $1 \mathrm{~min}$ followed by centrifugation for $10 \mathrm{~min}$ at $3000 \times \mathrm{g}$. The lower chloroform phase containing the lipid fraction was isolated. The methylation of fatty acids in this chloroform phase was also carried out as described by Havemose et al. (2004) with minor modifications. Two $\mathrm{mL}$ was evaporated to dryness under nitrogen. Fat (approximately $10 \mathrm{mg}$ ) was dissolved in sodium methylate $(1.0 \mathrm{~mL})$, and the tube was filled with argon and closed. After incubation at $60^{\circ} \mathrm{C}$ for $30 \mathrm{~min}$ and subsequent cooling on ice, saturated sodium chloride solution $(4.0 \mathrm{~mL})$ and pentane $(1.0 \mathrm{~mL})$ were added. The samples were mixed on a vortex-mixer for $1 \mathrm{~min}$ and centrifuged at $1700 \times g$ for $10 \mathrm{~min}$. The pentane phase was collected and used for gas chromatographic analysis as described below.

\subsubsection{Extraction of hexanal by solid phase microextraction (SPME) from milk}

The extraction of hexanal from the milk was carried out as described by Kristensen, Hedegaard, Nielsen, and Skibsted (2004), with minor modifications. Hexanal accumulated in the stored milk was analysed by SPME in combination with gas chromatography flame-ionization detection (GC-FID) equipment from Hewlett-Packard Co (Palo Alto, CA, USA). Milk $(2.00 \mathrm{~mL})$ was filled in a $4 \mathrm{~mL}$ headspace vial cleaned by a gas flame and with a glass-coated stirring bar. Sodium chloride $(0.25 \mathrm{~g})$ was added in order to get a salting out effect. An SPME fibre (Carboxen-PDMS, $75 \mu \mathrm{m}$ ) from Supelco (Bellefonte, PA, USA) was inserted in the headspace of the vial, and equilibrated for $30 \mathrm{~min}$ while the temperature at $45^{\circ} \mathrm{C}$ was thermostatically controlled.

\subsection{Separation and quantification}

\subsubsection{Total $\alpha$-tocopherol in milk and feed by HPLC}

Separation and quantification of tocopherols from milk and feed were carried out as described by Havemose et al. 
(2004), with minor modifications. Separation of tocopherols from other compounds was performed on a HPLC system (HP 1100, Hewlett-Packard Co., Palo Alto, CA, USA) with a Hypersil $\mathrm{Si}$ column $(25 \times 0.4 \mathrm{~cm})$. The injection volume was $30 \mu \mathrm{L}$, the mobile phase $n$-hexane:2propanol (98:2), and the flow rate $1.0 \mathrm{~mL}$ per $\mathrm{min}$. Detection was performed by fluorescence with excitation at $295 \mathrm{~nm}$ and with emission at $330 \mathrm{~nm}$. Quantification was performed by use of external standards.

\subsubsection{Isomeric distribution of $\alpha$-tocopheryl methyl ethers in milk and feed by HPLC}

Separation and quantification of $\alpha$-tocopheryl methyl ethers were performed as described by Riss et al. (1994), with minor modifications. Separation of the stereo-isomers of $\alpha$-tocopheryl methyl ethers from milk and feed was performed by HPLC (HP 1100 Series, Hewlett-Packard Co., Palo Alto, CA, USA) with a Chiralcel OD column $(25 \times 0.46 \mathrm{~cm}$; Daicel Chemical Industries Ltd., Illkirch, France). The injection volume was $100 \mu \mathrm{L}$, the mobile phase was $n$-hexane and the flow rate $1.0 \mathrm{~mL}$ per min. Detection was performed by fluorescence detection with excitation at $291 \mathrm{~nm}$ and emission at $330 \mathrm{~nm}$. Identification of the specific isomers was based on standards for $R R R-\alpha$ tocopherol and all-rac- $\alpha$-tocopherols as described by Riss et al. (1994).

\subsubsection{Fatty acids profile of milk by gas chromatography (GC)}

Separation and quantification of the fatty acid profile from milk were carried out as described by Havemose et al. (2004), with minor modifications. Samples of the pentane phase of the fatty acid methyl esters $(1.0 \mu \mathrm{L})$ were injected to a GC (HP6890 GC system, Hewlett-Packard Co., Palo Alto, CA, USA) with a flame-ionization detector and an HP-FFAP polyethylglycol TPA column $(25 \mathrm{~m} \times 0.2 \mathrm{~mm} \times$ $0.33 \mu \mathrm{m})$. The inlet temperature was $250{ }^{\circ} \mathrm{C}$, and the carrier gas was helium with a constant flow of $0.9 \mathrm{~mL}$ per min. The starting temperature at $40^{\circ} \mathrm{C}$ was held for $2 \mathrm{~min}$ and increased by $10^{\circ} \mathrm{C}$ per min to an end temperature of $240^{\circ} \mathrm{C}$, which was held for $10 \mathrm{~min}$ to a total run-time of $32 \mathrm{~min}$. Equilibration time was $0.50 \mathrm{~min}$. Identification was based on external standards, and calculation of the distribution (in weight percent) was based on the area of each fatty acid ester corrected for the response factors for the individual fatty acids.

\subsubsection{Detection of hexanal by SPME and GC in milk}

Detection of hexanal in milk was carried out as described by Kristensen et al. (2004), with minor modifications. Analyses of the volatiles absorbed to the SPME fibre were carried out by GC system from Hewlett-Packard Co., Palo Alto, CA, USA, using an HP-5 column (5\% phenyl methyl siloxane, $30 \mathrm{~m} \times 250 \mu \mathrm{m} \times 0.25 \mu \mathrm{m})$ and helium as carrier gas. Injection was performed in splitless mode with an injector temperature of $250^{\circ} \mathrm{C}$, and the volatile compounds were desorbed from the SPME fibre for $5 \mathrm{~min}$. The initial column temperature was $35^{\circ} \mathrm{C}$, which was held for $1 \mathrm{~min}$ and then raised by $10^{\circ} \mathrm{C}$ per min to $150^{\circ} \mathrm{C}$ and held for $1 \mathrm{~min}$. Then the temperature was raised again to $250^{\circ} \mathrm{C}$ by $30^{\circ} \mathrm{C}$ per min and held for $1 \mathrm{~min}$ to a total run-time of 18 min.

\subsubsection{Detection of ascorbyl radical by electron spin resonance (ESR)}

Detection of ascorbyl radical in milk was carried out as described by Steffensen, Andersen, and Nielson (2002), with minor modifications. The depletion of ascorbyl radicals induced by $\mathrm{Cu}^{2+}$ oxidation was followed over time in milk samples held at room temperature. Milk was transferred to an Eppendorf tube, and copper(II) sulphate was added to an end concentration of $100 \mu \mathrm{M}$. Milk samples were then transferred to an ESR capillary (Wilmad, Buena, NJ, USA), and each capillary was subsequently transferred to a Bruker EMX ESR X-band spectrometer (Bruker Analytische Messtechnik GMbH, Rheinstetten, Germany) with an ER 4119HS cavity. The time elapsed from addition of copper(II) sulphate to the moment when spectra were obtained was registered. The sample temperature was held at room temperature during measurements. The magnetic field was modulated with a frequency of $100 \mathrm{kHz}$ using a $2 \mathrm{G}$ field modulation amplitude, $20 \mathrm{~mW}$ of microwave power, and a receiver gain of $2 \times 10^{6}$. Sweep time was $84 \mathrm{~s}$, time constant $20.48 \mathrm{~s}$, and the spectra were obtained with 1024 pixels. Spectra were registered in the time mode, and all ESR measurements were performed three times.

\subsection{Statistical analysis}

The effect of $\alpha$-tocopherol supplementation in the diet on fatty acid composition, hexanal, and $\alpha$-tocopherol concentration and ascorbyl radical intensity in milk was assessed by comparing the relevant data from the two experiments. Statistical analysis of data was performed by using the General Linear Model procedure in the software package SAS $^{\circledR}$ version 8.1 (SAS Institute Inc., Cary, NC, USA). Mean values were calculated, and differences were regarded as significant at a minimum level of $95 \%(P<0.05)$.

\section{Results}

Fatty acid concentrations in the pooled milk samples before and after supplementation by all-rac- $\alpha$-tocopheryl acetate for both experiments (Table 1) were not different. However, there was a clear effect of the feeding strategy in experiment II, where the content of the unsaturated fatty acids, especially oleic acid $(\mathrm{C} 18: 1 ; P<0.001)$ and linoleic acid $(\mathrm{C} 18: 2 ; P<0.001)$, was significantly higher than in experiment $\mathrm{I}$.

Experiment I: The total content of $\alpha$-tocopherol was increased by $37 \%$ from 482 to $661 \mu \mathrm{g} \mathrm{L}^{-1}$ when the feed was supplemented with all-rac- $\alpha$-tocopheryl acetate (Table 2). When the feed did not contain supplemental 
Table 1

Means \pm standard deviation of fatty acid distribution in pooled milk samples $\left(\mathrm{g} 100 \mathrm{~g}^{-1}\right.$ fatty acid) from experiments I and II $^{\mathrm{a}}$

\begin{tabular}{|c|c|c|c|c|c|}
\hline & & \multicolumn{4}{|c|}{ 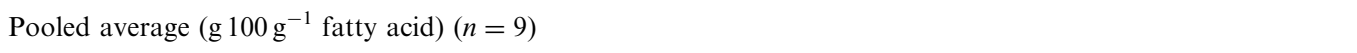 } \\
\hline & & \multicolumn{2}{|c|}{ Experiment I (2600 IU $\alpha$-tocopheryl acetate day ${ }^{-1}$ ) } & \multicolumn{2}{|c|}{ Experiment II (3400 IU $\alpha$-tocopheryl acetate day $^{-1}$ ) } \\
\hline & & Before suppl. & After three days of suppl. & Before suppl. & After 16 days of suppl. \\
\hline Butyric acid & $\mathrm{C} 4$ & $5.2 \pm 0.7$ & $4.6 \pm 0.7$ & $3.5 \pm 0.5$ & $3.1 \pm 0.6$ \\
\hline Caproic acid & $\mathrm{C} 6$ & $1.8 \pm 0.4$ & $1.7 \pm 0.4$ & $1.5 \pm 0.4$ & $1.4 \pm 0.4$ \\
\hline Caprylic acid & $\mathrm{C} 8$ & $1.1 \pm 0.3$ & $1.1 \pm 0.3$ & $0.8 \pm 0.3$ & $0.8 \pm 0.3$ \\
\hline Capric acid & $\mathrm{C} 10$ & $2.3 \pm 0.9$ & $2.3 \pm 0.8$ & $1.8 \pm 0.6$ & $1.7 \pm 0.5$ \\
\hline Lauric acid & $\mathrm{C} 12$ & $2.6 \pm 0.8$ & $2.7 \pm 0.8$ & $2.1 \pm 0.5$ & $2.0 \pm 0.4$ \\
\hline Myristic acid & $\mathrm{C} 14$ & $10.2 \pm 1.4$ & $10.4 \pm 1.4$ & $8.6 \pm 1.3$ & $8.3 \pm 1.2$ \\
\hline Palmitic acid & $\mathrm{C} 16$ & $24.9 \pm 1.5^{\mathrm{a}}$ & $24.9 \pm 1.4$ & $21.2 \pm 2.1^{\mathrm{cb}}$ & $21.6 \pm 2.0$ \\
\hline Palmitoleic acid & C16:1 & $2.0 \pm 0.3$ & $1.9 \pm 0.2$ & $1.7 \pm 0.2$ & $1.8 \pm 0.2$ \\
\hline Stearic acid & $\mathrm{C} 18$ & $11.3 \pm 1.0$ & $11.6 \pm 1.0$ & $13.0 \pm 1.4$ & $14.4 \pm 1.4$ \\
\hline Oleic acid & C18:1 & $34.1 \pm 5.1^{\mathrm{a}}$ & $34.4 \pm 4.9$ & $36.9 \pm 5.2^{\mathrm{cb}}$ & $36.1 \pm 4.4$ \\
\hline Linoleic acid & $\mathrm{C} 18: 2$ & $3.2 \pm 0.3^{\mathrm{a}}$ & $3.2 \pm 0.3$ & $6.8 \pm 0.6^{\mathrm{cb}}$ & $7.0 \pm 0.3$ \\
\hline Linolenic acid & $\mathrm{C} 18: 3$ & $1.2 \pm 0.2$ & $1.1 \pm 0.2$ & $2.1 \pm 0.6$ & $1.8 \pm 0.2$ \\
\hline
\end{tabular}

${ }^{a}$ Means between each experiment (before suppl.) with different superscript letters differ significantly $(P<0.05)$.

Table 2

Total content of $\alpha$-tocopherol (means \pm standard deviation) in the milk $\left(\mu \mathrm{g} \mathrm{L}{ }^{-1}\right)$, increase of $\alpha$-tocopherol in milk (\%), and relative distribution among $2 R$ and $2 S$-stereo-isomers of $\alpha$-tocopherol (\%) in pooled milk samples from experiments I and II

\begin{tabular}{|c|c|c|c|c|c|c|c|c|}
\hline & \multirow{2}{*}{$\begin{array}{l}\text { Days after } \\
\text { supplementation by all- } \\
\text { rac- } \alpha \text {-tocopheryl } \\
\text { acetate to the feed }\end{array}$} & \multirow{2}{*}{$\begin{array}{l}\text { Total content of } \alpha \text { - } \\
\text { tocopherol in milk } \\
\left(\mu \mathrm{g} \mathrm{L}^{-1}\right)\end{array}$} & \multirow{2}{*}{$\begin{array}{l}\text { The increase of } \alpha \text { - } \\
\text { tocopherol in the milk } \\
(\%)^{\mathrm{a}}\end{array}$} & \multicolumn{4}{|c|}{$\begin{array}{l}\text { Relative distribution among the } 2 R \text {-stereo- } \\
\text { isomers }(\%)\end{array}$} & \multirow{2}{*}{$\begin{array}{l}2 S \text {-stereo-somers } \\
(S R R, S S R, S S S, \\
S R S)\end{array}$} \\
\hline & & & & $R S S^{\mathrm{b}}$ & $R R S$ & $R R R$ & $R S R$ & \\
\hline \multirow[t]{2}{*}{ Exp. I } & 0 & $439 \pm 12$ & & 2.4 & 2.9 & 92.6 & 2.1 & $\mathrm{ND}^{\mathrm{c}}$ \\
\hline & 3 & $599 \pm 32$ & 37 & 6.4 & 4.9 & 84.3 & 4.4 & ND \\
\hline \multirow[t]{2}{*}{ Exp. II } & 0 & $742 \pm 42$ & & 1.5 & 0.6 & 97.1 & 0.8 & ND \\
\hline & 16 & $804 \pm 25$ & 29 & 4.6 & 3.7 & 88.8 & 2.9 & ND \\
\hline
\end{tabular}

${ }^{\text {a }}$ The increase of $\alpha$-tocopherol in the milk (\%) from day 0 to day 3 (experiment I) and from day 0 to day 16 (experiment II) in percentage (after suppl. -before suppl./before suppl. $\times 100 \%$ ).

${ }^{\mathrm{b}} R S S, R R S, R R R, R S R, S R R, S S R, S S S, S R S$ are the abbreviations of the eight $\alpha$-tocopherol stereo-isomers.

${ }^{\mathrm{c}} \mathrm{ND}$ : not detectable.

all-rac- $\alpha$-tocopheryl acetate, the proportion of the synthetic $2 R$-stereo-isomers of $\alpha$-tocopherol ( $R S S$-, $R R S$-, and $R S R$ $\alpha$-tocopherol) was $2.4 \%, 2.9 \%$, and $2.1 \%$, respectively, which was rather low. The native $R R R$ - $\alpha$-tocopherol dominated in the milk with $92.6 \%$ of the total $\alpha$-tocopherol content. When the feed was supplemented, the contributions of the three synthetic $2 R$-isomers were increased to $6.4 \%, 4.9 \%$, and $4.4 \%$, respectively. None of the $2 S$ stereo-isomers were detected in the milk before or after supplementation by all-rac- $\alpha$-tocopheryl acetate.

The four cows received an average of $513 \mathrm{mg}$ natural $\alpha$ tocopherol per cow per day from the feed and $1810 \mathrm{mg}$ all$r a c$ - $\alpha$-tocopheryl acetate from the $\alpha$-tocopherol supplement, which gave a total of $2323 \mathrm{mg} \alpha$-tocopherol per cow per day. The stereo-isomers of $\alpha$-tocopherol were distributed as follows: $226 \mathrm{mg} \mathrm{day}^{-1}$ of $R R R$-stereo-isomers, $679 \mathrm{mg} \mathrm{day}^{-1}$ of the synthetic $2 R$-stereo-isomers, and $905 \mathrm{mg} \mathrm{day}^{-1}$ of the $2 S$-stereo-isomers. If absorption was non-discriminative, the contribution of $\alpha$-tocopherol stereo-isomers would be $31.8 \%$ of the natural form of $\alpha$ tocopherol (RRR- $\alpha$-tocopherol), $29.2 \%$ of the synthetic $2 R$-stereo-isomers, and $39.0 \%$ of the synthetic $2 S$-stereoisomers. However, the actual distribution of the stereoisomers in the milk was $84.3 \%, 15.7 \%$, and $0.0 \%$, respectively, indicating a high degree of discriminative absorption.

The formation of hexanal was not significantly different $(P=0.79)$ in the two milk types during the storage period under fluorescent light (Fig. 1). The $\alpha$-tocopherol concentration in milk sampled before and after dietary $\alpha$ tocopherol supplementation declined over the $24 \mathrm{~h}$ storage period. This decline was apparently largest in milk from cows given supplemental all-rac- $\alpha$-tocopherol. Nevertheless, the final $\alpha$-tocopherol concentration was still significantly higher in milk taken from cows after supplementation $(P<0.01)$ (Fig. 2). 


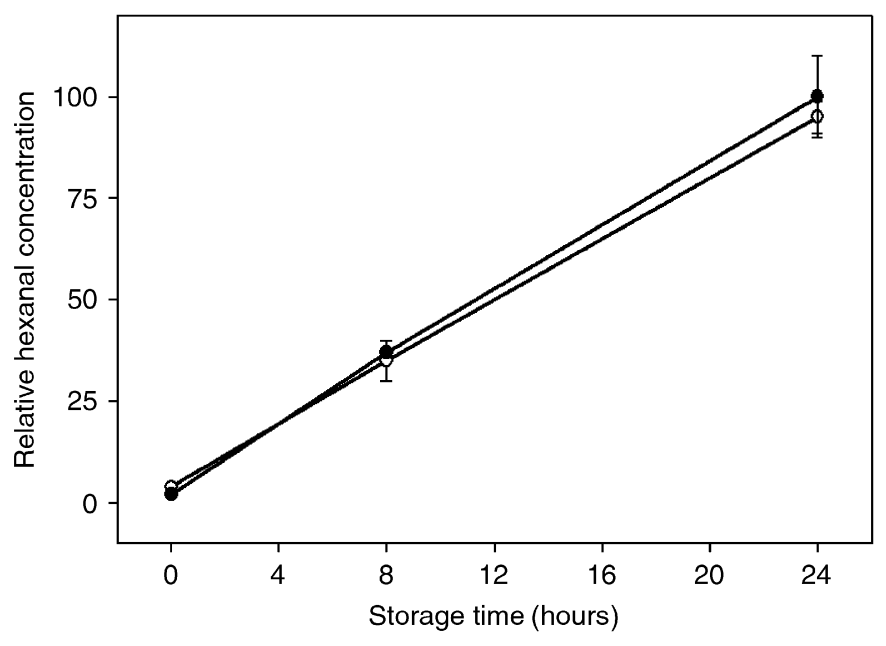

Fig. 1. Accumulation of hexanal (relative concentration) in milk exposed to fluorescent light $(2200 \mathrm{~lx})$ for $24 \mathrm{~h}$ at $4{ }^{\circ} \mathrm{C}$ and coming from cows fed on a diet without any supplementation by all-rac- $\alpha$-tocopheryl acetate $(O)$, and after supplementation of the feed with $2600 \mathrm{IU}$ of all-rac- $\alpha$-tocopheryl acetate for three days (-) (experiment I). Vertical bars indicate the standard deviation.

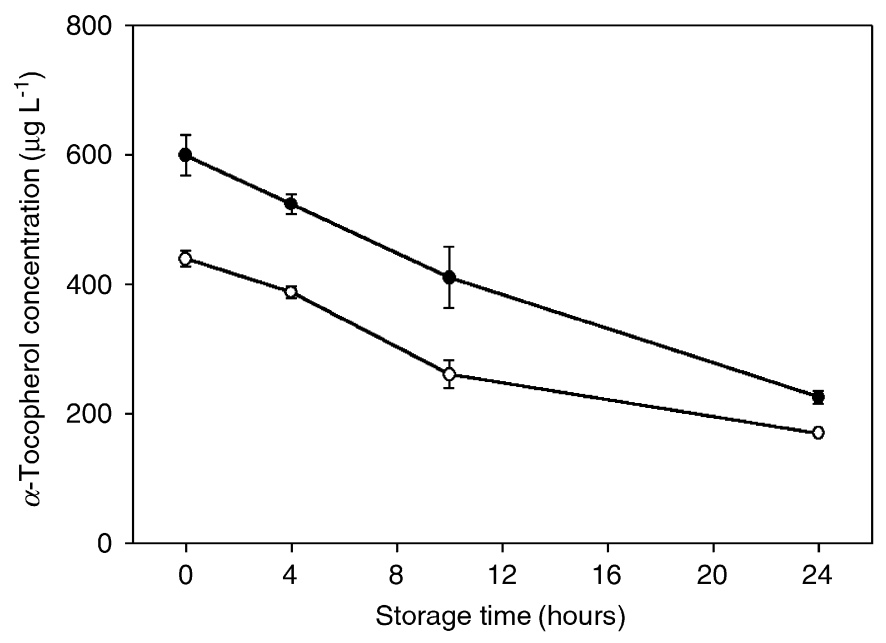

Fig. 2. Concentration of $\alpha$-tocopherol $\left(\mu \mathrm{g} \mathrm{L}^{-1}\right)$ in milk exposed to fluorescent light (2200 lx) for $24 \mathrm{~h}$ at $4{ }^{\circ} \mathrm{C}$ and coming from cows fed on a diet without $(O)$ or with supplementation of the feed with $2600 \mathrm{IU}$ of all$r a c-\alpha$-tocopheryl acetate for three days $(\bullet)$ (experiment I). Vertical bars indicate the standard deviation.

Experiment II: Before supplementation the content of $\alpha$ tocopherol in the pooled milk samples was approximately $700 \mu \mathrm{g} \mathrm{L}^{-1}$ (Table 2). After seven days of supplementation, the content of $\alpha$-tocopherol in the milk had increased to approximately $900 \mu \mathrm{gL}^{-1}$ (data not shown), and the content of $\alpha$-tocopherol remained constant throughout the rest of the feeding experiment. This gave a total increase of $29 \%$ of $\alpha$-tocopherol after supplementation.

The longer depletion period prior to the period of supplementation in experiment II compared with experiment $I$ and the different types of feed affected the distribution of $\alpha$-tocopherol stereo-isomers. The $R R R-\alpha$ - tocopherol isomer in experiment II constituted as much as $97.1 \%$ of the total $\alpha$-tocopherol in the milk (Table 2). The remaining $2.9 \%$ of synthetic stereo-isomers could have originated from the small amount of $\alpha$-tocopherol present in the mineral supplementation, determined by analysis in our laboratory (data not shown) and which was not declared on its recipe. After 16 days of supplementation by all-rac- $\alpha$-tocopheryl acetate the ratio of the synthetic $\alpha$ tocopherol stereo-isomers increased to $11.2 \%$ of the total $\alpha$-tocopherol content in the milk. This was less than that in experiment I; it should be noted that the concentration of natural $\alpha$-tocopherol in the feed was higher in the soya bean-based feed compared with the feed used in experiment I (data not shown). Furthermore, it should be emphasized that none of the $2 S$-stereo-isomers was detected in the milk in any of the experiments.

The three cows received on average $907 \mathrm{mg}$ natural $\alpha$ tocopherol from the feed per cow per day and $2151 \mathrm{mg}$ all$r a c-\alpha$-tocopherol from the vitamin supplement, which gave a total of $3058 \mathrm{mg}$ all-rac- $\alpha$-tocopherol per cow per day. The distribution of the $\alpha$-tocopherol stereo-isomers in the all-rac- $\alpha$-tocopheryl acetate supplement was as follows: $269 \mathrm{mg} \mathrm{day}^{-1}$ for the $R R R$-stereo-isomer, $807 \mathrm{mg} \mathrm{day}^{-1}$ for the synthetic $2 R$-stereo-isomers, and $1075 \mathrm{mg} \mathrm{day}^{-1}$ for the $2 S$-stereo-isomers. Based on this estimated intake, the expected distribution of the $\alpha$-tocopheryl stereo-isomers in milk would be $38.5 \%, 26.4 \%$, and $35.1 \%$, respectively, provided that there was no discrimination between the stereo-isomers. However, the actual distribution found for the isomers in the milk was $88.8 \%, 11.2 \%$, and $0.0 \%$, respectively, again indicating a high degree of discriminative absorption.

The accumulation of hexanal during $24 \mathrm{~h}$ of exposure to fluorescent light at $2.200 \mathrm{~lx}$ was significantly lower in the milk without any supplementation by all-rac- $\alpha$-tocopheryl acetate (Fig. 3), compared with the accumulation of

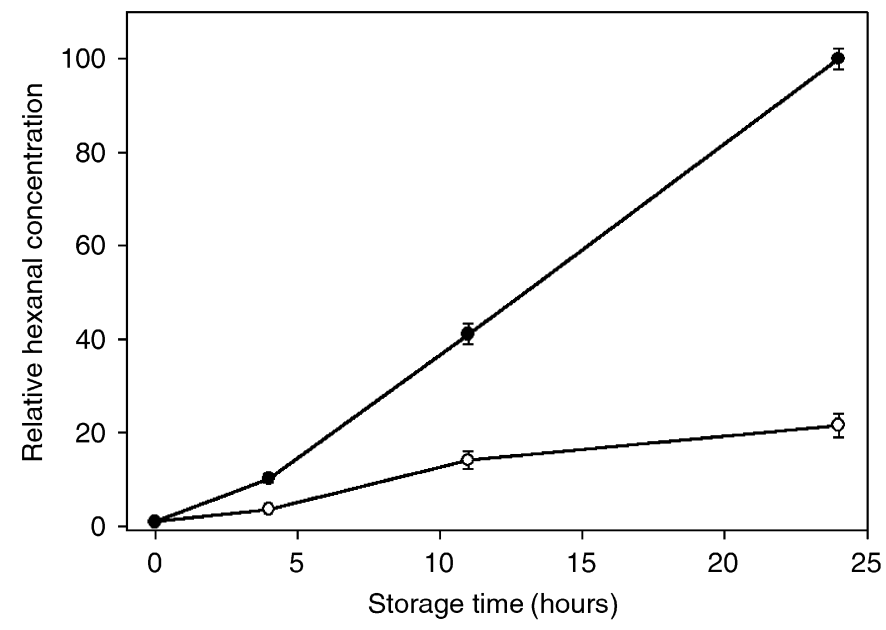

Fig. 3. Accumulation of hexanal (relative concentration) in milk exposed to fluorescent light $\left(2200 \mathrm{~lx}\right.$ ) for $24 \mathrm{~h}$ at $4{ }^{\circ} \mathrm{C}$ and coming from cows fed on a soya bean-based diet without $(O)$ or with supplementation of the feed with $3400 \mathrm{IU}$ of all-rac- $\alpha$-tocopheryl acetate for 16 days (-) (experiment II). Vertical bars indicate the standard deviation. 
hexanal in milk produced after supplementation $(P<0.001)$. This was in marked contrast to the results obtained in experiment I. The content of $\alpha$-tocopherol decreased more rapidly in the milk from cows receiving the supplemented feed $(P<0.001)$ (Fig. 4). During the $24 \mathrm{~h}$ storage period the levels approached each other and were not significantly different after $24 \mathrm{~h}$, irrespective of whether the cows had been receiving all-rac- $\alpha$-tocopheryl acetate supplementation or not.

In milk stored for $24 \mathrm{~h}$ with added copper(II) sulphate there was a significantly higher accumulation of hexanal in milk collected after 16 days of supplementation compared with the milk collected before supplementation $(P<0.001$; Table 3). Only a small decrease in the content of $\alpha$ tocopherol was detected in both milk types. The content of $\alpha$-tocopherol in the milk collected after 16 days of all-rac- $\alpha$ tocopheryl acetate supplementation was initially higher, but in milk collected after 16 days of supplementation following initiation of oxidation with $\mathrm{Cu}^{2+}$ the decrease in the content of $\alpha$-tocopherol during storage was significantly lower $(P<0.01)$.

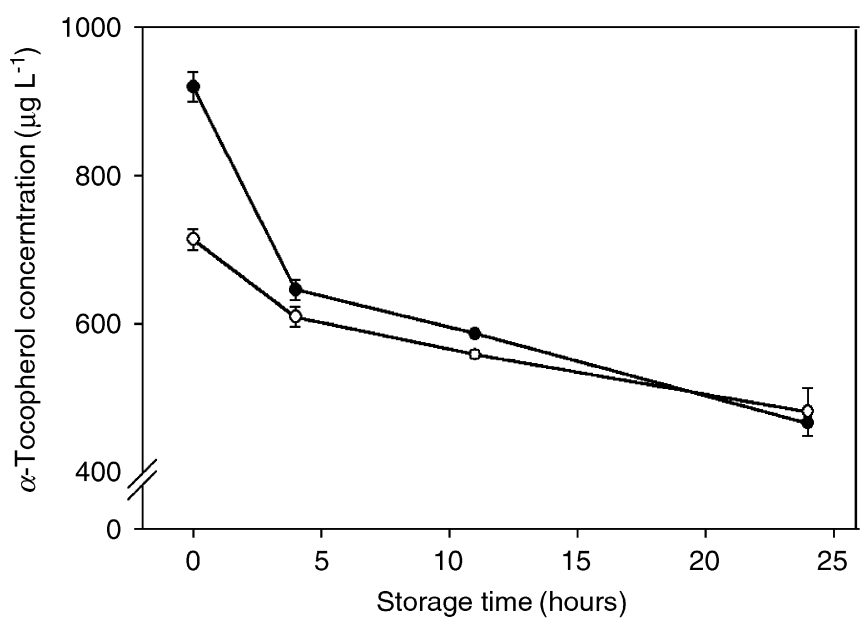

Fig. 4. Effect of storage time on concentration of $\alpha$-tocopherol $\left(\mu \mathrm{g} \mathrm{L}^{-1}\right)$ in milk exposed to fluorescent light $(2200 \mathrm{~lx})$ for $24 \mathrm{~h}$ at $4{ }^{\circ} \mathrm{C}$ and coming from cows fed on a soya bean-based diet without $(O)$ or with supplementation of the feed with $3400 \mathrm{IU}$ of all-rac- $\alpha$-tocopheryl acetate

(0) (experiment II). Vertical bars indicate the standard deviation.
$\mathrm{Cu}^{2+}$ induces oxidation and radical formation in the aqueous phase of the milk and in order to monitor those processes, the formation and subsequent depletion of the ascorbyl radical were followed by ESR-spectroscopy (Fig. 5). The initial rate of depletion of the ascorbyl radical was higher in the milk from cows receiving the supplement than in milk from cows not receiving the supplement. Furthermore, the time required for complete depletion of the ascorbyl radical was shorter in milk collected from the cows receiving supplement by all-rac- $\alpha$-tocopheryl acetate $(13 \mathrm{~min})$ than in the milk collected prior to supplementation $(17 \mathrm{~min} ; P<0.05)$. There were no ascorbyl radicals present in either of the two milk types after $5 \mathrm{~h}$ at $4{ }^{\circ} \mathrm{C}$, when the milk had copper(II) sulphate added to an end concentration of only $25 \mu \mathrm{m}$ (data not shown).

\section{Discussion}

Synthetic $\alpha$-tocopherol, as, for example, all-rac- $\alpha$-tocopheryl acetate, has been used as a feed supplement for years in order to improve the oxidative stability of milk.

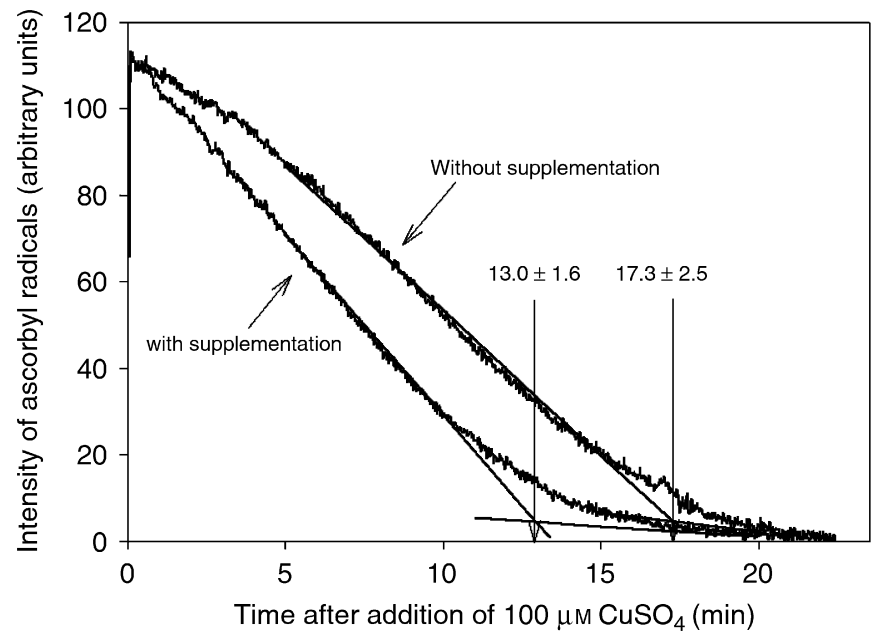

Fig. 5. Occurrence of ascorbyl radical (relative intensity) in milk containing copper(II) sulphate with an end concentration of $100 \mu \mathrm{m}$ at room temperature and coming from cows fed on a soya bean-based diet without any supplementation by all-rac- $\alpha$-tocopheryl acetate and after supplementation of the feed with $3400 \mathrm{IU}$ of all-rac- $\alpha$-tocopheryl acetate for 16 days (experiment II).

Table 3

LS mean \pm standard deviation of the accumulation of hexanal (arbitrary units) and concentration of $\alpha$-tocopherol $\left(\mu \mathrm{g} \mathrm{L}^{-1}\right)$ in milk from experiment II

\begin{tabular}{llcl}
\hline Exp. day & Storage time with $25 \mu \mathrm{M} \mathrm{CuSO}(\mathrm{h})$ & Relative concentration of hexanal & $\alpha$-tocopherol $\left(\mu \mathrm{g} \mathrm{L}{ }^{-1}\right)$ \\
\hline Day 0 & 0 & $16.7 \pm 1.5$ & $742.4 \pm 42.4$ \\
& 24 & $31.3 \pm 3.3$ & $658.9 \pm 29.1$ \\
Day 16 & 0 & $25.6 \pm 3.2$ & $803.7 \pm 25.1$ \\
& 24 & $111.1 \pm 7.8$ & $768.3 \pm 20.1$ \\
$P$-value & Experiment day & $<0.0001$ & $<0.01$ \\
& Storage time & $<0.0001$ & $<0.01$ \\
& Experiment day $\times$ storage time & $<0.0001$ & $\mathrm{NS}$ \\
\hline
\end{tabular}


However, previous studies have indicated that supplementation with high concentrations of all-rac- $\alpha$-tocopheryl acetate only gave rise to a modest increase of $\alpha$-tocopherol in the milk (St-Laurent et al., 1990). In the present studies the feed for dairy cows was supplemented with high concentrations of all-rac- $\alpha$-tocopheryl acetate compared with the content of natural $\alpha$-tocopherol present in the feed. Nevertheless, the content of $\alpha$-tocopherol in the milk only increased by $37 \%$ in experiment I and $29 \%$ in experiment II (Table 2). In experiment I it has to be taken into consideration that both the depletion period, where the cows did not receive any supplements, and the subsequent supplementation period were rather short. Development of a new chromatographic method to separate the stereo-isomers of $\alpha$-tocopherol made it possible to follow the excretion of native and synthetic $\alpha$ tocopherol stereo-isomers to the milk, and the results have shown that only the four $2 R$-stereo-isomers of $\alpha$-tocopherol, of which one is natural and three are synthetic, were excreted into the milk, while the synthetic $2 S$-stereoisomers were not detected in the milk. The three synthetic $2 R$-stereo-isomers of $\alpha$-tocopherol were only excreted to the milk in low concentrations (Table 2) compared with the amount fed to the animal. These new results can explain results of previous studies, in which cows were given a dietary supplementation of all-rac- $\alpha$-tocopheryl acetate without any consistent increase in the $\alpha$-tocopherol concentration in milk (Atwal et al., 1990; St-Laurent et al., 1990). Accordingly, it may be concluded that supplementation of the feed with all-rac- $\alpha$-tocopheryl acetate is an ineffective way to increase the content of $\alpha$-tocopherol in milk.

In experiment I the accumulation of the lipid oxidation product, hexanal, was similar in milk with high and low content of $\alpha$-tocopherol (with and without supplementation of all-rac- $\alpha$-tocopheryl acetate) when the milk was exposed to fluorescent light (Fig. 1), and it can be concluded that the supplementation of the feed with $2600 \mathrm{IU} \mathrm{day}^{-1}$ of all-rac- $\alpha$-tocopheryl acetate is not capable of improving the oxidative stability of milk. In experiment II the milk fat from the dairy cows was highly unsaturated (Table 1), and in this experiment, supplementation by all$r a c-\alpha$-tocopheryl acetate increased the concentration of $\alpha$ tocopherol in the milk by $29 \%$ (Table 2 ), while the fatty acid composition of the milk was unaffected. Exposure of the two different milk types to fluorescent light gave an accumulation of hexanal, but it is noteworthy that the accumulation of hexanal was higher (Fig. 3) in the milk with the high amount of $\alpha$-tocopherol (with supplementation by all-rac- $\alpha$-tocopheryl acetate).

Former studies showed that $\alpha$-tocopherol acts as a physical quencher of singlet oxygen, which is formed by photosensitization, and it is only degraded when deactivating singlet oxygen (Bowry \& Stocker, 1993). However, in the present study the $\alpha$-tocopherol was found to be oxidized, suggesting as described by Fragata and Bellemare (1980) that chemical quenching of singlet oxygen is important in milk. The degradation of $\alpha$-tocopherol in milk exposed to light (Figs. 2 and 4) indicated clearly that the chemical quenching or direct reaction between peroxyl radicals or other oxygen radicals and $\alpha$-tocopherol resulted in degradation of $\alpha$-tocopherol in milk.

Tocopherols are important chain-braking anti-oxidants, and they deactivate peroxyl radicals formed by transition metal ion-propagated oxidation (Kamal-Eldin \& Appelqvist, 1996). Notably, propagation of the oxidation in the two milk types in experiment II as induced by copper(II) showed that milk with a high content of $\alpha$-tocopherol (after supplementation by all-rac- $\alpha$-tocopheryl acetate) is more exposed to metal-catalysed oxidation than milk with a low content of $\alpha$-tocopherol before supplementation by all-rac$\alpha$-tocopheryl acetate (Table 3 ). It was further shown that decay of ascorbyl radical formed by $\mathrm{Cu}^{2+}$ catalysis was more pronounced in milk with a high concentration of $\alpha$ tocopherol indicating a higher oxidative stress (Fig. 5) than in milk with a low concentration of $\alpha$-tocopherol. The prooxidative effect of $\alpha$-tocopherol has been described earlier by Pokorny (1987) for model systems, and was assigned to the reaction of tocopheryl radicals, formed during oxidation with metals like $\mathrm{Cu}^{2+}$ and $\mathrm{Fe}^{3+}$, and thereby propagated oxidation by initiation of new reaction chains. Likewise, Kamal-Eldin and Appelquist (1996) have suggested that $\alpha$-tocopherol can act as a co-pro-oxidant, when present at high concentrations together with pro-oxidants like transition metal ions and lipid hydroperoxides. This hypothesis was confirmed by the results of experiment II, in which the milk had a high content of polyunsaturated fatty acids, and oxidation was accelerated by storage in light or by addition of copper(II). The combination of oxidative stress and a high level of oxidation substrates such as linoleic and linolenic acid leads $\alpha$-tocopherol to act as a copro-oxidant.

\section{Conclusion}

This study clearly shows that supplementation of the feed for dairy cows with high concentrations of all-rac- $\alpha$ tocopheryl acetate did not improve the oxidative stability of milk. Two factors seem important in this respect: (1) only the $2 R$-stereo-isomers and mainly the natural $R R R$ stereo-isomer are excreted into the milk and (2) in milk with high levels of $\alpha$-tocopherol and with unsaturated fat, the $\alpha$-tocopherol seems to become pro-oxidative. However, mechanistic studies are necessary in order to understand the balance between anti- and pro-oxidative attributes of $\alpha$ tocopherol in the milk.

\section{Acknowledgements}

The authors thank the Danish Dairy Research Foundation (Danish Dairy Board), the Danish Research Centre for Organic Farming (DARCOF), and the Danish Research School for Organic Agriculture and Food Systems (SOAR) for financial support. The authors would 
also like to thank Ivan Nielsen at the Danish Institute of Agricultural Sciences for technician assistance in the laboratory.

\section{References}

Atwal, A. S., Hidiroglou, M., Kramer, J. K. G., \& Binns, M. R. (1990). Effects of feeding $\alpha$-tocopherol and calcium salts of fatty acids on vitamin E and fatty acid composition of cow's milk. Journal of Dairy Science, 73, 2832-2841.

Bowry, V. W., \& Stocker, R. (1993). Tocopherol-mediated peroxidationThe prooxidant effect of vitamin $\mathrm{E}$ on the radical-initiated oxidation of human low-density-lipoprotein. Journal of the American Chemical Society, 115, 6029-6044.

Charmley, E., \& Nicholson, J. W. G. (1994). Influence of dietary fat source on oxidative stability and fatty acid composition of milk from cows receiving a low or high level of dietary vitamin E. Canadian Journal of Animal Science, 74, 657-664.

Charmley, E., Nicholson, J. W. G., \& Butler, G. (1991). Effect of intramuscular injection of $\alpha$-tocopherol on its concentration in blood plasma and milk. Journal of Dairy Science, 74, 274.

Charmley, E., Nicholson, J. W. G., \& Zee, J. A. (1993). Effect of supplemental vitamin $\mathrm{E}$ and selenium in the diet on vitamin $\mathrm{E}$ and selenium levels and control of oxidized flavor in milk from Holstein cows. Canadian Journal of Animal Science, 73, 453-457.

Dunkley, W. L., Ronning, M., Franke, A. A., \& Robb, J. (1967). Supplementing ratios with tocopherol and ethoxyquin to increase oxidative stability of milk. Journal of Dairy Science, 50, 492-499.

Fragata, M., \& Bellemare, F. (1980). Model of singlet oxygen scavenging by $\alpha$-tocopherol in biomembranes. Chemistry and Physics of Lipids, 27, 93-99.

Goering, H. K., Gordon, C. H., Wrenn, T. R., Bitman, J., King, R. L., \& Douglas, F. W. (1976). Effect of feeding protected safflower oil on yield, composition, flavor, and oxidative stability of milk. Journal of Dairy Science, 59, 416-425.

Gorman, A. A., Gould, I. R., Hamblett, I., \& Standen, M. C. (1984). Reversible exciplex formation between singlet oxygen, $1-\delta-g$, and vitamin E-Solvent and temperature effects. Journal of the American Chemical Society, 106, 6956-6959.

Havemose, M. S., Weisbjerg, M. R., Bredie, W. L. P., \& Nielsen, J. H. (2004). Influence of feeding different types of roughage on the oxidative stability of milk. International Dairy Journal, 14, 563-570.

IUPAC-IUB. (1982). Nomenclature of tocopherols and related-compounds. IUPAC-IUB Joint Commission on Biochemical Nomenclature (Jcbn). Retrieved September 1, 2005, from: 〈http://www.chem. qmul.ac.uk/iupac/misc/toc.html .

Jensen, S. K., Jensen, C., Jakobsen, K., Engberg, R. M., Andersen, J. O., Lauridsen, C., et al. (1998). Supplementation of broiler diets with retinol acetate, $\beta$-carotene or canthaxanthin: Effect on vitamin status and oxidative status of broilers in vivo and on meat stability. Acta Agriculturae Scandinavica Section A, 48, 28-37.

Kamal-Eldin, A., \& Appelqvist, L.-A. (1996). The chemistry and antioxidant properties of tocopherols and tocotrienols. Lipids, 31, 671-701.

Kristensen, D., Hedegaard, R. V., Nielsen, J. H., \& Skibsted, L. H. (2004). Oxidative stability of buttermilk as influenced by the fatty acid composition of cows' milk manipulated by diet. Journal of Dairy Research, 71(1), 46-50.

Krukovsky, V. N., Whiting, F., \& Loosli, J. K. (1950). Tocopherol, carotenoid and vitamin A content of the milk fat and the resistance of milk to development of oxidized flavors as influenced by breed and season. Journal of Dairy Science, 33, 791-796.

Nicholson, J. W. G., \& St-Laurent, A.-M. (1991). Effect of forage type and supplemental dietary vitamin $\mathrm{E}$ on milk oxidative stability. Canadian Journal of Animal Science, 71, 1181-1186.

Nielsen, J. H., Østdal, H., \& Andersen, H. J. (2002). The influence of ascorbic acid and uric acid on the oxidative stability of raw and pasteurized milk. In M. J. Morello, F. Chahidi, \& C.-T. Ho (Eds.), Free radicals in food-Chemistry, nutrition and health effects, Vol. 807 (pp. 126-137). Washington, DC, USA: American Chemical Society Symposium Series.

Niki, E., Yamamoto, Y., Takahashi, M., Komuro, E., \& Miyama, Y. (1989). Inhibition of oxidation of biomembranes by tocopherol. Annals of the New York Academy of Sciences, 570, 23-31.

Pokorny, J. (1987). Major factors affecting the autoxidation of lipids. In H. W. S. Chan (Ed.), Autoxidation of unsaturated lipids (pp. 141-206). London, UK: Academic Press.

Riss, G., Kormann, A. W., Glinz, E., Walther, W., \& Ranalder, U. B. (1994). Separation of the eight stereoisomers of all-rac- $\alpha$-tocopherol from tissues and plasma: Chiral phase high-performance liquid chromatography and capillary gas chromatography. Methods in Enzymology, 234, 302-310.

Schingoethe, D. J., Parsons, J. G., Ludens, F. C., Schaffer, L. V., \& Shave, H. J. (1979). Response of lactating cows to $300 \mathrm{mg}$ of supplemental vitamin E daily. Journal of Dairy Science, 62, 333-338.

Schingoethe, D. J., Parsons, J. G., Ludens, F. C., Tucker, W. L., \& Shave, H. J. (1978). Vitamin E status of dairy cows fed stored feeds continuously or pastured during summer. Journal of Dairy Science, $61,1582-1589$.

Steffensen, C. L., Andersen, H. J., \& Nielsen, J. H. (2002). Aldehydeinduced xanthine oxidase activity in raw milk. Journal of Agricultural and Food Chemistry, 50(25), 7392-7395.

St-Laurent, A.-M., Hidiroglou, M., Snoddon, M., \& Nicholson, J. W. G. (1990). Effect of $\alpha$-tocopherol supplementation to dairy cows on milk and plasma $\alpha$-tocopherol concentrations and on spontaneous oxidized flavor in milk. Canadian Journal of Animal Science, 70, 561-570. 